\title{
Does treatment of Helicobacter Pylori Infection Reduce Gastric Precancerous Lesions?
}

\author{
Fariborz Mansour-Ghanaei ${ }^{1 *}$, Farahnaz Joukar ${ }^{1}$, Kourosh Mojtahedi ${ }^{1}$, \\ Homayoon Sokhanvar ${ }^{1}$, Kourosh Askari², Ahmad Shafaeizadeh ${ }^{3}$
}

\begin{abstract}
Background: Treatment of Helicobacter pylori $(H$. pylori) decreases the prevalence of gastric cancer, and may inhibit gastric precancerous lesions progression into gastric cancer. The aim of this study was to determine the effect of treatment on subsequent gastric precancerous lesion development. Materials and Methods: We prospectively studied 27 patients who had low grade dysplasia at the time of enrollment, in addition to dysplasia atrophic gastritis and intestinal metaplasia observed in all patients. All were prescribed quadruple therapy to treat $\mathrm{H}$. Pylori infection for 10 days. Patients underwent endoscopy with biopsy at enrollment and then at follow up two years later. Biopsy samples included five biopsies from the antrum of lesser curvature, antrum of greater curvature, angularis, body of stomach and fundus. Results of these biopsies were compared before and after treatment. Results: Overall, the successful eradication rate after two years was 15/27 (55.6\%). After antibiotic therapy, the number of patients with low grade dysplasia decreased significantly $(p=0.03)$, also with reduction of the atrophic lesions $(p=0.01)$, but not metaplasia. Conclusions: Treatment of $H$. pylori likely is an effective therapy in preventing the development of subsequent gastric premalignant lesions.
\end{abstract}

Keywords: H. Pylori - treatment - gastric precancerous lesions

Asian Pac J Cancer Prev, 16 (4), 1571-1574

\section{Introduction}

Nearly 70 percent of gastric cancers (714000 cases) are occurring in developing countries (Ferlay et al., 2010). Northern provinces of Iran specially Ardabil and Guilan are high risk regions from the point of gastric cancer (Fallah, 2007; Atrkar-Roushan et al., 2013). Precancerous lesions in gastric cancer include atrophic gastritis (AG), intestinal metaplasia (IM) and dysplasia that are preventable by effective treatment. Gastric cancer is divided to well differentiated and undifferentiated intestinal forms (Shah et al., 2011). Undifferentiated intestinal form cancers are related to Helicobacter pylori (H.pylori) and since this infection develops in childhood, so it needs a long period till the cancer occurs (Correa 1992; Feldman et al., 2010). H. pylori infection, AG and IM are well-known risk conditions for gastric carcinoma (Slpponen et al., 1985).

Studies have shown that $H$.pylori can lead to a twofold increased risk of gastric adenocarcinoma (Huang et al., 1998; Eslick et al., 1999). Uemura et al. (2001) have shown that there is an H.pylori infection in all people who suffer from cancer in Japan. Also was suggested that the gastric cancer can be prevented by $H$. pylori eradication (Dan et al., 2006), and some experts believe that H.pylori treatment can prevent gastric cancer and precancerous lesions (Malfertheiner et al., 2005; Fuccio et al., 2007). This bacterial infection causes chronic active gastritis in all infected people. The surface inflammation begins in antrum and will progress slowly to spread in all of the stomach. In later stages mucosal atrophy, metaplasia and dysplasia will occur in $40 \%-50 \%$ of the infected people. After treatment of the H.pylori infection, the inflammation and atrophic process will reduce (Curado et al., 2008; Ferlay et al., 2010).

Although, the increasing risk of adenocarcinoma following $H$.pylori infection depends on different factors including bacteria species, host genetic factors, infection period and the existence of other environmental risk factors (cigarette, improper nutrition) (Feldman et al., 2010). The prevalence of gastric cancer has decreased drastically in last decade. Part of this decrease change in H.pylori infection and other environmental and nutritious factors (Curado et al., 2008). This study was undertaken to determine the effect of eradication of H.pylori on the development of gastric premalignant lesions. 


\section{Materials and Methods}

This research is a part of a large-scaled study for gastric cancer designed to assess epidemiological aspects, prevalence of precancerous lesions and early gastric cancer among people more than 50 years that the results has been published in Asian Pacific Journal of Cancer Prevention (Mansour-Ghanaei et al., 2012). It was a nonrandomized open label clinical trial conducted throughout a period of 24 months in the Gastrointestinal and Liver Diseases Research Center (GLDRC) in Guilan University of Medical Sciences (GUMS). This research was approved by ethics committee of GLDRC, and parental consent was obtained. The study population consisted of the 35 patients who were diagnosed low grade dysplasia in histopathologic evaluation of Lashtenesha research project (Mansour-Ghanaei, 2012; Shafaghi et al., 2012). All of them had also AG, IM and positive rapid urease test (RUT). Thirty-five patients received quadruple therapy with proton pomp inhibitor and antimicrobial treatment to eradicate H.pylori, including Clarithromycin $500 \mathrm{mg}$, Amoxicillin $1000 \mathrm{mg}$, Bismuth sub citrate 240 $\mathrm{mg}$, Pantoprazol $40 \mathrm{mg}$ all twice daily for 10 days and 27 patients completed the study. Eight patients left this research: six failed to continue the study, and two died due to cardiovascular event. After two year, gastroscopy was performed for twenty-seven patients by gastroenterologist. Biopsy samples included five biopsies from the antrum of lesser curvature, antrum of greater curvature, angularis, body of stomach and fundus were taken and fixed in $10 \%$ formalin. Biopsies were examined by the pathologist in a blind manner. A further biopsy specimen was taken for assessment for H.pylori by RUT which used for diagnosis of H. pylori. The data was then entered into SPSS 13. Fisher's exact test or, when appropriate, the chi-square test (both two tailed) were used for Categorical variables.
Continuous variables were analyzed by the Student's t test. Significance of differences and relations were determined by $\mathrm{p}$ values of $<0.05$.

\section{Results}

This study was conducted on 35 patients with gastric precancerous lesions, among which, 27 received eradication therapy for H. Pylori. The baseline characteristics of these Patients are summarized in Table 1.

The successful eradication rate after two years was $15 / 27(55.5 \%)$ overall. The frequency of premalignant lesions in twenty-seven patients after treatment are shown in table2.

After treatment, the number of patients with dysplasia and atrophic lesions decreased significantly $(\mathrm{p}=0.03$ and

Table 1. Baseline Characteristics of 27 Patients

\begin{tabular}{llc}
\hline Sex & Male & $15(55.6 \%)$ \\
& Female & $12(44.4 \%)$ \\
& Age(year) & $64.8 \pm 10.8$ \\
Age Groups & & \\
& $50-59$ & $13(48.2 \%)$ \\
& $60-69$ & $5(18.5 \%)$ \\
& $70 \geq$ & $9(33.3 \%)$ \\
\hline
\end{tabular}

Table 2. Number of Patients with Precancerous Lesions two Years After $H$. pylori Treatment

\begin{tabular}{lcc}
\hline Lesion & & Frequency $(\%)$ \\
\hline Atrophic Gastritis & No & $23(85.2)$ \\
& Yes & $4(14.8)$ \\
Intestinal metaplsia & No & $9(33.3)$ \\
& Yes & $18(66.7)$ \\
Dysplasia & No & $21(77.8)$ \\
& Yes & $6(22.2)$ \\
\hline
\end{tabular}

Table 3. Comparison of Histopathological Grades in Three Types of Lesions Prior to H. pylori Therapy and Two Years After Treatment According to the Site of Lesions

\begin{tabular}{|c|c|c|c|c|c|c|}
\hline \multirow[t]{2}{*}{$\begin{array}{l}\text { Types of Lesion (sites)* } \\
\text { Grade }\end{array}$} & \multicolumn{2}{|c|}{$\begin{array}{c}\text { Mild } \\
\text { Frequency }(\%)^{* *}\end{array}$} & \multicolumn{2}{|c|}{$\begin{array}{c}\text { Moderate } \\
\text { Frequency }(\%)\end{array}$} & \multicolumn{2}{|c|}{$\begin{array}{c}\text { Severe } \\
\text { Frequency }(\%)\end{array}$} \\
\hline & Prior to therapy & After therapy & Prior to therapy & After therapy & Prior to therapy & After therapy \\
\hline \multicolumn{7}{|l|}{ Atrophic Gastritis } \\
\hline Site1 & $7(25.9)$ & $5(18.5)$ & $5(18.5)$ & $0(0)$ & $0(0)$ & $0(0)$ \\
\hline Site2 & $6(21)$ & $1(3.7)$ & $1(3.7)$ & $0(0)$ & $1(3.7)$ & $0(0)$ \\
\hline Site3 & $7(25.9)$ & $1(3.7)$ & $0(0)$ & $0(0)$ & $1(3.7)$ & $0(0)$ \\
\hline Site4 & $4(14.8)$ & $0(0)$ & $2(7.4)$ & $0(0)$ & $0(0)$ & $0(0)$ \\
\hline Site5 & 1(3.7) & $0(0)$ & $0(0)$ & $0(0)$ & $0(0)$ & $0(0)$ \\
\hline \multicolumn{7}{|l|}{ Intestinal Metaplasia } \\
\hline Site1 & $7(25.9)$ & $7(25.9)$ & $5(18.5)$ & $3(11.1)$ & $3(11.1)$ & $1(3.7)$ \\
\hline Site2 & $5(18.5)$ & $6(22.2)$ & $4(14.8)$ & $2(7.4)$ & 1(3.7) & $2(7.4)$ \\
\hline Site3 & $7(25.9)$ & $2(7.4)$ & $3(11.1)$ & $1(3.7)$ & $1(3.7)$ & $1(3.7)$ \\
\hline Site4 & $3(11.1)$ & $4(14.8)$ & $2(7.4)$ & $1(3.7)$ & $0(0)$ & $2(7.4)$ \\
\hline Site 5 & $1(3.7)$ & $1(3.7)$ & $2(7.4)$ & $0(0)$ & $0(0)$ & $0(0)$ \\
\hline \multicolumn{7}{|l|}{ Dysplasia } \\
\hline Site1 & $13(48.1)$ & $1(3.7)$ & $0(0)$ & $0(0)$ & $0(0)$ & $0(0)$ \\
\hline Site2 & $9(33.3)$ & $2(7.4)$ & $0(0)$ & $0(0)$ & $0(0)$ & $0(0)$ \\
\hline Site3 & $4(14.8)$ & $1(3.7)$ & $0(0)$ & $0(0)$ & $0(0)$ & $0(0)$ \\
\hline Site4 & $5(18.5)$ & $1(3.7)$ & $0(0)$ & $0(0)$ & $0(0)$ & $0(0)$ \\
\hline Site 5 & $2(7.4)$ & $1(3.7)$ & $0(0)$ & $0(0)$ & $0(0)$ & $0(0)$ \\
\hline
\end{tabular}

*Site 1. Antrum of lesser curvature; Site 2. Antrum of greater curvature; Site 3. Angularis; Site 4. Body of stomach; Site 5. Fundus; **Values are presented as patient number $(\%)$ 
Table 4. The Relationship Between Lesions Improvement and H.pylori Eradication after Two Years

\begin{tabular}{lccc}
\hline Lesion & & $\begin{array}{c}\text { H.pylori } \\
\text { eradication } \\
\text { YES }\end{array}$ & $\begin{array}{c}\text { H.pylori } \\
\text { eradication } \\
\text { NO }\end{array}$ \\
\hline Dysplasia & No & $14(93.3)$ & $7(58.3)$ \\
& Yes & $1(6.7)$ & $5(41.7)$ \\
Intestinal Metaplasia & No & $6(40)$ & $3(25)$ \\
& Yes & $9(60)$ & $9(75)$ \\
Atrophic & No & $15(100)$ & $8(66.7)$ \\
& Yes & $0(0)$ & $4(33.4)$ \\
\hline
\end{tabular}

$\mathrm{p}=0.01$ respectively, both examined by the Fisher's exact test), but not in metaplasia lesions $(\mathrm{p}=0.4)$.Sex was not associated with healing of gastric precancerous lesions after $H$. pylori treatment in none of three groups ( $\mathrm{p}>0.05$ by the Fisher's exact test)

\section{Analysis by biopsy site}

Specimens were reviewed by pathologists and scored using (Dixon et al., 1996; Schlemper et al., 2000) a mild, moderate and sever (in grade) for AG, IM and dysplasia and compared with specimens before antimicrobial treatment. We compared the grade of lesions prior to $H$. pylori therapy and two year after treatment according to the site of lesions. There were statistically significant differences the grade of atrophic lesions $(\mathrm{p}=0.01$ by Student's t-test) and dysplasia ( $\mathrm{p}=0.045$ by Student's t-test). These changes were not statistically significant in metaplasia $(\mathrm{p}=0.13)$. The results are shown in Table 3 .

Frequency of lesions two years after primary treatment based on the patients who are still suffering from $H$.pylori and who are healed of $H$. pylori is shown Table 4.

\section{Discussion}

The association between premalignant lesions and adenocarcinoma of the stomach is well known. The natural course of gastric precancerous lesions, especially dysplasia, is not well established. Gastric premalignant lesions such as AG or dysplasia are detected during routine endoscopy. H.pylori causes chronic active gastritis, which progresses through dysplasia to gastric adenocarcinoma (Correa, 1992). Also, the ideal regimen (more than ninety percent eradication rate) for the treatment of $H$. pylori infection has not yet been defined (Cuena 2002; Treiber et al., 2002; Vakil and Megraud 2007).

The results of this study suggest that the $H$. pylori eradication rate was $55.5 \%$ after treatments. The reason for the lower eradication rates is not clear. Of course, the eradication rate of an infection will vary in different conditions, such as: bacterial resistance to drugs, bacterial virulence, increased susceptibility of hosts to $H$. pylori infection and re-exposure to $H$. pylori are proposed to be the major requirements for re-infection of H.pylori (Xia and Talley 1997; Xia 1997; SM Rahman 2005). Another reason was that we checked $H$. pylori two years after the treatment, so some patients may be re-infected during this time. Studies in Iran indicate one and three year reinfection rate after successful eradication to be $19 \%$ and $20 \%$, respectively (Malekzadeh et al., 2004).

Statistical results indicated that there was a meaningful statistical relationship between the regression of dysplasia and $A G$ and eradication rate, it means that infection treatment reduces the dysplasia and atrophy. We compared precancerous lesions according to histopathologic grade (mild, moderate or severe) in five biopsy sites before treatment and two years after that. In atrophy and dysplasia grade changes were statistically significant. Our findings showed the $80 \%$ of GA, $25 \%$ IM and $82 \%$ of dysplasia to improve. Ohkusa et al. (2001) suggested that the $89 \%$ of GA and $61 \%$ of IM healed following the treatment of H.pylori infection. Also, Lu et al. (2005) reported $75 \%$ of GA and 51\% of IM recovered. Chon et al. (2013) research indicates that there was a relationship between H.pylori infection therapy and regression of dysplasia, so that results matched with our findings in declining of dysplasia. Vander Hulst et al. (1997) reported that the rate of atrophy and metaplasia did not change considerably after treatment of infection. Kokkola et al. (2002) study also suggested the healing of metaplasia following the treatment of H.pylori infection. The reasons for these discrepancies between two recent researches and our study may be due to the difference in follow-up time, sample size, quantity and location of biopsy specimens and histological standard. Also the results indicated that there is no statistical difference between patients with dysplasia, atrophy and metaplasia by gender, before and after the treatment of H.pylori infection. So, it can be concluded that the eradication rate did not associate to gender. Chon et al. (2013) demonstrated there was no significant difference between the treatment and sex.There are some limitations to our study. First, this was a nonrandomized open label clinical trial study with a small sample size, this may threaten generalizability of the results. Second, $H$. pylori eradicated rate was low, so we should find other drugs regimen to get high eradication rate. Third, a more sufficient follow-up time may be needed to evaluate the long-term effect of eradication therapy on gastric metaplasia. We suggest further investigations with larger sample sizes to estimate the relationship between demographic indices including gender, age and smoking and the improvement of precancerous lesions

Considering the main goal of this research, studying of precancerous lesions following the treatment of $\mathrm{H}$ .pylori, the result of this research indicated that the lesions like dysplasia and atrophy reduced after treatment and there was a significant statistical relationship between treatment of H.pylori infection and reduction of dysplasia and atrophy. Although statistical analysis showed no association between the treatment of this infection and regression of metaplasia, larger sample size could show different results or the metaplasia lesions it may need more than two year time to observe the differences.

\section{Acknowledgements}

This study was supported financially by grants from the Gastrointestinal and Liver Diseases Research Center (GLDRC) of Guilan University of Medical Sciences. Authors would like to thanks all members of GLDRC for 
Fariborz Mansour-Ghanaei et al

their help in preparation all data. None of the authors has any conflict of interest to declare.

\section{References}

Atrkar-Roushan Z, Kazemnejad A, Mansour-Ghanaei F, et al (2013). Trend analysis of gastrointestinal cancer incidences in Guilan province: comparing rates over 15 years. Asian Pac J Cancer Prev, 14, 7587-93.

Chon I, Choi Ch, Shin Ch, et al (2013). Effect of Helicobacter pylori eradication on subsequent dysplasia development after endoscopic resection of gastric dysplasia. Korean $J$ Gastroenterol, 61, 307-12.

Correa P (1992). Human gastric carcinogenesis: a multistep and multifactorial process-first American Cancer Society award lecture on cancer epidemiology and prevention. Cancer Res, 52, 6735-40.

Cuena BR (2002). Ranitidine-bismuth citrate versus omeprazole plus two antibiotics for seven days for the eradication of helicobacter pylori: a non-concluding clinical essay. Ann Med Interna, 19, 439-40

Curado MP (2008). International agency for research on cancer, and World Health Organization cancer incidence in five continents.

Dan YY, JBY S, Khay G, et al (2006). Endoscopic screening for gastric cancer. Clinic Gastroenterol Hepato, 14, 709-16.

Dixon MF, Genta RM, Yardley JH, et al (1996). Classification and grading of gastritis: the updated Sydney system. Am J Surg Pathol, 20, 1161-81.

EslickGD, Lim, Lynette LY, Julie E, et al (1999). Association of helicobacter pylori infection with gastric carcinoma: a meta-analysis. Am J Gastroenterol, 94, 2373-79.

Fallah M (2007). Cancer incidence in five provinces of Iran: Ardebil, Gilan, Mazandaran, Golestan and Kerman, 19962000. J University Tampere, 24, 14-27.

Feldman M, Lawrence SF, Lawrence JB(2010). Sleisenger and Fordtran's Gastrointestinal and Liver Disease: Pathophysiology, Diagnosis, Management, Expert Consult Premium Edition-Enhanced Online Features. Volume 1: Elsevier Health Sciences.

Ferlay J, Shin, HR, Bray F, et al (2010). Estimates of worldwide burden of cancer in 2008: GLOBOCAN 2008. Int J Cancer, 127, 2893-17.

Fuccio L, Zagari RM, Minardi ME, et al (2007). Systematic review: Helicobacter pylori eradication for the prevention of gastric cancer. Aliment Pharmacol Ther, 25, 133-41.

Huang JQ, Sridhar S, Chen Y, et al (1998). Meta-analysis of the relationship between helicobacter pylori seropositivity and gastric cancer. Gastroenterol, 114, 1169-79.

Kokkola A, Sipponen P, Rautelin H, et al (2002). The effect of helicobacter pylori eradication on the natural course of atrophic gastritis with dysplasia. Aliment Pharmacol Ther, 16, 515-20.

Malekzadeh R, Mohamadnejad M, Siavoshi F, et al (2004). Treatment of Helicobacter pylori infection in Iran: low efficacy of recommended western regimens. Arch Iranian Med, 7, 1-8.

Malfertheiner P, Sipponen P, Naumann M, et al (2005). Helicobacter pylori eradication has the potential to prevent gastric cancer: a state-of-the-art critique. Am j Gastroenterol, 100, 2100-15.

Mansour-Ghanaei F, Sokhanvar H, Joukar F, et al (2012). Endoscopic findings in a mass screening program for gastric cancer in a high risk region-Guilan province of Iran. Asian Pac J Cancer Prev 13, 1407-12.

Schlemper RJ, Riddell RH, Kato Y, et al (2000). The Vienna classification of gastrointestinal epithelial neoplasia. Gut,
47, 251-5.

Shafaghi A, Mansour-Ghanaei F, Joukar F,et al (2012). Serum gastrin and the pepsinogen I/II ratio as markers for diagnosis of premalignant gastric lesions. Asian Pac J Cancer Prev, 14, 3931-6.

Shah MA, Khanin R, Tang L, et al (2011). Molecular classification of gastric cancer: a new paradigm. Clin Cancer Res, 17, 2693-01.

Slpponen P, Kekki M, Haapakoski J, et al (1985). Gastric cancer risk in chronic atrophic gastritis: Statistical calculations of cross-sectional data. Int J Cancer, 35, 173-7.

Rahman SM , Hasan M (2005). Helicobacter pylori infection and duodenal ulcer disease in bangladesh. J Banagladesh Coll Phys Surg, 23, 50-98.

Treiber G, Ammon S, Malfertheiner P, et al (2002). Impact of furazolidone-based quadruple therapy for eradication of helicobacter pylori after previous treatment failures. Helicobacter, 7, 225-31.

Nimish V , Megraud F,(2007). Eradication therapy for helicobacter pylori. Gastroenterol, 133, 985-01.

Van der Hulst RW, Van der Ende AD, Friedo W, et al (1997). Effect of helicobacter pylori eradication on gastritis in relation to cag A: a prospective 1-year follow-up study. Gastroenterol, 113, 25-30.

Xia HH, Talley NJ (1997). Natural acquisition and spontaneous elimination of Helicobacter pylori infection: clinical implications. Am J Gastroenterol, 92, 1780-7.

Xia HH, Talley NJ, Keane CT, et al (1997). Recurrence of Helicobacter pylori infection after successful eradication: nature, possible causes and potential preventive strategies. Digest Dis Sci, 42, 1821-34. 